\title{
The Influence of the Big-Five Personality Traits Dimensions on Knowledge Sharing Behavior
}

\author{
Maliheh Lotfi ${ }^{1}$ \\ Syaharizatul Noorizwan Bt. Muktar² \\ Andrew C. Ologbo 3 \\ Kingsley C. Chiemeke ${ }^{4}$ \\ 1,2,3,4 Faculty of Management, Universiti Teknologi Malaysia (UTM), 81310 Skudai, Johor, Malaysia \\ 2izatul.muktar@gmail.com, 3andrewologbo@yahoo.com, ${ }^{4}$ chiemekekingsleychiedu@yahoo.com \\ Corresponding author:1lotfi_maliheh@yahoo.com
}

\section{Doi:10.5901/mjss.2016.v7n1s1p241}

\section{Abstract}

The purpose of this paper is to examine the influence of the Big-Five personality (BFP) dimensions on individual's knowledge sharing behavior. In this paper, we empirically investigated the effect of personality traits (extraversion, openness, conscientiousness, agreeableness, and neuroticism) on knowledge sharing behavior among academics in a public university in Malaysia. A questionnaire-based survey was employed for the data collection. A total of 133 academic staff members participated in the survey. The findings showed that personality traits dimension are important characteristic that influence knowledge sharing. Openness to experience, extroversion and conscientiousness has positive significant influence on individuals' knowledge sharing behavior. Also, the results indicated that openness to experience appears to be the most significant factor influencing of knowledge sharing. Although agreeableness among academic staff has an influence on their knowledge sharing behavior yet it is not statistically significant. As expected, neuroticism had negative significant influence on the knowledge sharing.

Keywords: Knowledge Sharing, Big-Five Personality Traits, Agreeableness, Neuroticism.

\section{Introduction}

In the business world today, many firms have come to the realization that knowledge is a major sources of competitive advantage and that it plays a great role in the long-term success, growth and sustainability of any organization (Davenport and Prusak, 1998). Managing organizational knowledge has being identified by researchers (Davenport and Prusak, 1998; Wang and Noe, 2010; Bollinger and Smith, 2001) as a strategic means for organizations to improve their performance, become more innovative, gain new markets and sustain competitive advantage. Knowledge sharing is considered the most crucial process of knowledge management (Gupta and Govindarajan, 2000) and according to Jarvenpaa and Staples (2001) individuals are the principal agent of knowledge sharing and the main source of knowledge in the organization. Since individuals' in the organization plays an important role in knowledge sharing process through collectively sharing experiences and insights to create new knowledge, it is therefore important to examine the influence individual's personality traits dimensions on knowledge sharing behavior. This is the central aim of this study.

There are evidences that individual's characteristics, personality trait dimensions could influence knowledge sharing behaviour (Hsu et al., 2007; Matzler et al 2008; Gupta 2008). Within the individual characteristics, personality is an important psychological factor that guides individuals' behaviour. Thus, an employee's personality characteristic is a critical factor that impacts on that employee's behaviour to share or not to share knowledge. To this regard, the aim of this study is to enhance the understanding of personality and knowledge sharing relationship. Based on this aim, the objective of this study is to investigate the influence of personality trait dimensions (namely agreeableness, openness, neuroticism, extraversion and conscientiousness) on knowledge sharing behavior. Interestingly, the debate on the influence of employee's personality traits on knowledge sharing is centred on the point that though individuals could possess the knowledge necessary to move their organization forward, yet, the individual characteristics of the knowledge possessor could be a major barrier to knowledge sharing. Whilst knowledge sharing has been well studied in the 
organizational setting, Fullwood et al (2013) lamented that not much have been done on knowledge sharing in the academic institutions.

To enter into the debate of examining personality characteristics and knowledge sharing in the academic setting, this study tends to raise the issue that understanding the personality of academics and their knowledge sharing behaviour would be useful for knowledge-based institutions, such as universities, where knowledge creation, dissemination, utilization and application are embedded in their learning, research and publication activities. The next section is devoted to the conceptual clarification of some basic concepts utilised in this study. Discussions on the concepts of knowledge, knowledge management, knowledge sharing and personality trait dimensions are presented followed by a brief review of the existing studies on knowledge sharing and personality traits research domain.

\section{Knowledge}

First we make a critical distinction between data, information and knowledge. According to some authors (Bellinger et al., 2004; Bollinger and Smith, 2001) data is raw elements and numbers, information is processed data, while knowledge is information combined with human thoughts. Data transform into information when it adds value while information transforms into knowledge when it adds insights and better understanding. According to Bennet and Bennet, (2000), knowledge is a combination of data and information that gives a best understanding of a situation, relationships, casual phenomena, theories and rules. Davenport and Prusak (1998) described knowledge as value framed experience, expert insights and contextual information which gives a road map for assessing new information and experience. Tiwana (2000) views knowledge as actionable information available in the exact format, at the exact time, and at the exact place for decision making.

The concept of knowledge and knowledge management in firms is gaining increasing popularity in the academic literature (Alvesson and Karreman, 2001), with knowledge being acknowledged a crucial resource for organizational performance and competitive advantage (Wang and Noe, 2010), critical to the sustainable organizational success and performance (Nonaka and Takeuchi, 1995). Knowledge which is a valuable resource is embodied in individual employees and embedded in organization and could enable organizations to innovate and compete (Bollinger and Smith, 2001). Individual employees possess a unique set of knowledge gotten from prior experiences and sources accumulated over the years. This uniqueness of knowledge makes it difficult to imitate and substitute making it to be the most valuable organizational resource (Grant, 1996; Zack, 1999).

\subsection{Knowledge Management}

Knowledge management despite been an important area of research over two decades, still the concept has some difficulties in finding a universal accepted common ground. The literature summarizes the concept as the application of knowledge in the organizations via its human capital, or as knowledge assets stored in the organizations as database, routines, and patents, channeled towards the value-creation of the firm. In general, knowledge management focuses on managing and facilitating knowledge-related activities, such as creation, capture, transformation and the use of knowledge (Lin, 2007). Awad and Ghaziri (2004) posited a valuable description of knowledge management as a multiple process that encompasses the utilization of knowledge from external sources, storage and application of knowledge to improve organizational products, processes and services, embedding knowledge into databases and repositories, promotion of knowledge advancement via the organizational culture and reward mechanisms, dissemination of knowledge throughout the firm as well as the assessment of the value and the impact of knowledge resources. Knowledge management had four processes namely knowledge discovery, knowledge capture, knowledge sharing, knowledge application (Becerra-Fernandez et al., 2004). In this study, emphasizes is only on knowledge sharing.

\subsection{Knowledge Sharing}

According to Gupta and Govindarajan (2000), knowledge sharing could be described as the major process of knowledge management which encompasses the process of identifying the outflow and inflow of knowledge in activities that involves the transfer or dissemination of knowledge resources from one person to another or from one group to another within the organization. Van den Hooff et al (2003) views knowledge sharing as a process where employees' exchange both tacit and explicit knowledge to create new knowledge. In addition, Hendriks (1999) emphasized that the process knowledge sharing is essential for organizations because it provides a useful channel by which knowledge residing within individual employees is collectively transferred to form organizational knowledge where it is utilized to create economic value and 
sustainable advantage for the organization at large.

Successful implementations of knowledge sharing processes can assist organizations in improving their innovation capability (Lin, 2007), add value to organizational activities (Mitchell, 2009), reduce redundant learning efforts (Calantone et al, 2002; Scarbrough, 2003), increased productivity (Quigley et al. 2007), and improved employees as well as firm performance (Verburg and Andriessen, 2011). Therefore, knowledge sharing behaviour which is degree to which an individual actually share their knowledge with others (Lin and Lee) is considered as the key focus of this study.

\subsection{Previous Studies on Knowledge Sharing}

There are existing studies (Gupta, 2008; Hsieh et al, 2011; Yusof and Ismail, 2010) that examined knowledge sharing using the personality theory. Studies conducted by Gupta (2008) studied the role played by personality in influencing knowledge acquisition and knowledge sharing behaviour using 156 management students as it respondents. The findings of his study show that agreeableness and conscientiousness had significant influence on knowledge sharing but found no significant difference in knowledge sharing and knowledge acquisition participation between individuals with high or low extraversion, openness and neuroticism. Hsieh et al., (2011) explored the relationship among five factors of personality traits and innovation with the mediating role of knowledge management. The research was conducted on workers of the biotechnology industry in Taiwan. The survey questionnaire technique was used for data collection. Data were analysed through a statistical method of hierarchical regression. Their study showed that employees in biotechnology with big five personality traits, exclusive of agreeableness, positively impact their innovation capability and make them more creative.

Yusof and Ismail (2010) studied the impact of awareness, trust and personality on knowledge sharing practices among 428 employees working with government agencies in Malaysia. They found that a significant relationship between awareness, trust, personality and knowledge sharing. Their finding implies that knowledge sharing practice is influenced by awareness, trust and personality of the employees involved in the knowledge sharing process. Teh et al. (2011) studied the influence of big-five personality dimensions on knowledge sharing using 255 Malaysian university students. The findings of their study showed that extraversion and neuroticism has positive significant relationship with the students' attitude to share knowledge.

Lin and Wang (2012) examined the impact of personality traits dimensions on knowledge withholding intentions among university students. According to their conceptualization, knowledge withholding intentions refer to students' tendency to decide whether to conceal useful knowledge that would have been beneficial to other students. They also noted that knowledge withholding behaviour among students is a hindrance to social knowledge development in the context of educational or University setting. Their study did not provide empirical validation but build upon the claims of previous studies that personality traits influence knowledge sharing behaviour. Furthermore, Matzler et al. (2008) studied personality traits and knowledge sharing among 600 civil, mechanical, or electrical engineers. They found agreeableness, conscientiousness and openness trait dimensions to have significant correlation with knowledge sharing behaviour.

Based on the review of the existing literature on personality and knowledge sharing research area, it was found that nearly all studies that used the big five personality theory have not extensively examined it to a logical conclusion. Some examined only two or three dimensions of personality traits. For instance Matzler et al (2008) studied only agreeableness, conscientiousness and openness. While other researchers (e.g. Lin and Wang, 2012), did not provide empirical validation. For this reason, this study would attempt to study personality traits in depth by considering all the five dimensions of personality traits suggested by the big five theory. This study therefore devote a keen interest to study the influence of personality traits on knowledge sharing because although individual could possess the useful knowledge however if such an individual has negative personality characteristics, that useful knowledge would not be shared and adequately utilized by other fellow colleagues in the organization. Examining personality traits dimensions could help explain how different dimensions of individual characteristics would enhance or discourage their participation in knowledge sharing.

\subsection{Personality Traits}

Personality trait is an organised and dynamic set of characteristic which an individual possess that distinctively impacts his or her cognition, motivation and behaviour (Ryckman, 2004). The elements of the big five theory of personality traits was first initiated the original work of McDougall (1932). The "Big-Five" theory consists of five dimensions which are developed by the works of authors such as Cattell and Kline (1977) and Eyskenck and Eyskenck (1985). These five traits are extroversion, neuroticism, agreeableness, conscientiousness and openness to experience. Discussions on these five dimensions are presented in the next section. Figure 1 presents the research model showing the correlation between 
personality trait dimensions and knowledge sharing behaviour.

\subsubsection{Agreeableness}

Barrick and Mount (1991) described agreeableness personality dimension as denoting individuals who are helpful, decent, courteous, generous, cheerful, and co-operative. Knowledge sharing is described as a practice where employees commonly disseminate their explicit and tacit knowledge for the creation of new knowledge (Rivera-Vazquez et al., 2009). This study suggests that since people high in agreeableness are very helpful, good natured and cooperative with others thus they could most probably participate in knowledge sharing. Their friendly nature could enable them to easily maintain close relationship with others. Previous studies have suggested that people with high agreeableness never feel hesitate to share their information, experience and best practices. Matzler et al (2008) found that agreeableness has significant impact on knowledge sharing. Thus, this study suggests that people high in agreeableness would be more willing to engage in knowledge sharing.

H1: Agreeableness would have a positive influence on individuals' knowledge sharing behaviour.

\subsubsection{Openness to Experience}

Openness denotes the dimension of personality trait which is characterised by the individuals' active imagination, intellectual curiosity, aesthetic sensitivity, vivid imaginative, and independence of judgment (Barrick and Mount, 1991; LePine and Van Dyne, 2001). In their study, Cabrera et al (2006) revealed that openness to experience is a dominant factor impacting on knowledge sharing because openness reflects an individual's originality and curiosity disposition which in most cases influence them to seek insights from other people. Thus, it can be expected that individuals high in openness would most like develop more expertise than others with low openness. As proposed by Constant et al (1996), individuals' with high level of expertise would most likely give more valuable advice to others. In addition, Wasko and Faraj, (2005) mentioned that people are less likely to contribute their knowledge if they perceive that expertise is not adequate. Individuals with high degree of openness to experience would more likely to seek and contribute knowledge. Therefore, second hypothesis is stated as follow:

H2: Openness would have a positive influence on individuals' knowledge sharing behaviour.

\subsubsection{Neuroticism}

Neuroticism encompasses various negative dispositions namely sadness, nervousness and worriedness (Benet-Martinez and John 1998). Probably, individuals with high levels of neuroticism would not cooperate or engage in knowledge sharing with other individuals. According to Gupta (2008) an individual high in neuroticism is inclined to display anxiety, depression, anger, fearfulness and insecurity moods in public. Therefore, this study suggest that since of neuroticism will impact on individuals interaction with others in a common space; it could possibly influence their participation in knowledge sharing activities. Previous studies did not provide evidence of a significant correlation between neuroticism and knowledge sharing. Studies conducted by Wang and Yang (2007) showed no significant correlation between neuroticism and knowledge sharing intentions. Therefore, the third hypothesis is stated as:

H3: Neuroticism would have a negative influence on individuals' knowledge sharing behaviour.

\subsubsection{Extraversion}

Extraversion is characterized by individual's tendency to be active, assertive, sociable, energetic, adventurous, and communicative (Barrick et al., 2002). Thus, it could be said that individual who display high extraversion would participate in knowledge sharing more than others with low extraversion. Previous studies have suggested that extraversion has a significant impact on knowledge sharing. Studies conducted by De Vries et al, (2006) found extraversion to positively influence knowledge sharing. A recent study conducted by Wang et al., (2014) found that extrovert individuals would share their knowledge whether there is reward or no reward. A logically explanation for their findings may be related to the assumptions that people high in extraversion would be inclined to gain status as suggested by Barrick et al (2005). Therefore, this study argues that extrovert individuals tend to share knowledge because of their sociable and expressive nature. The fourth hypothesis is stated as follow:

H4: Extraversion would have a positive influence on individuals' knowledge sharing behaviour. 


\subsubsection{Conscientiousness}

Mount (1991) described conscientiousness as the characteristics of people who are reliable, dutiful, organized, responsible, goal-oriented and hardworking. Debatable, one could claim that individuals with high conscientiousness are more likely to participate in knowledge sharing activities. Some existing studies have found conscientiousness to be related to knowledge sharing. For example, studies conducted by Matzler et al., (2008) as well as Wang and Yang, (2007) found a significant relationship to knowledge sharing. However, studies carried out by Cabrera et al. (2006) and Teh, et al (2011) failed to show a significant correlation between conscientiousness and knowledge sharing behaviour. Based on these, this current study argues that individuals high with conscientiousness would most likely participate in knowledge sharing. Thus, the last hypothesis is stated as:

H5: Conscientiousness would have a positive influence on individuals' knowledge sharing behaviour.

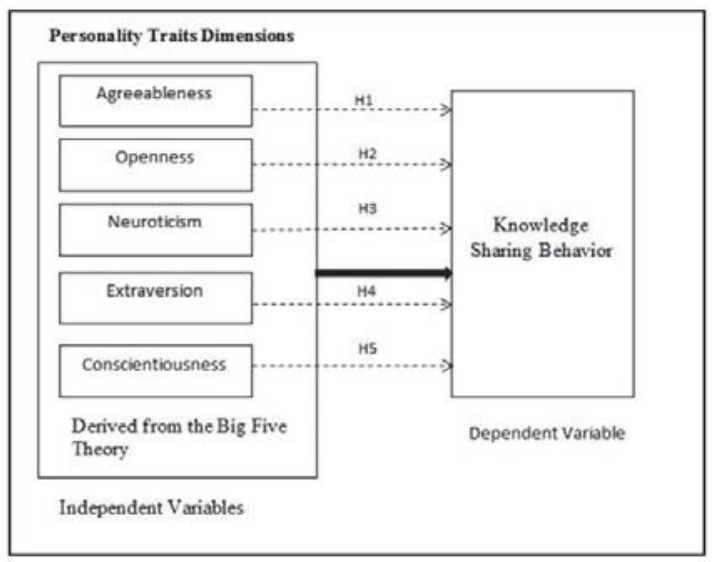

Figure 1: Research Model

\section{Methodology}

The quantitative method using survey technique was employed to gather data for this study. In total, 185 questionnaires were randomly distributed to the academic staff in a research university in Malaysia. Out of the 185 questionnaires distributed, 133 questionnaires were completed and returned indicting a response rate of $71.9 \%$. The data was empirically tested using the multiple regressions analysis through the SPSS software version 21.

Measures: The dimensions of personality traits, agreeableness and openness are measured using the items derived from Soto and John (2009); neuroticism and extraversion are measured using the instrument developed by moon et al 2014 while conscientiousness is measured using the instrument developed by Matzler and Mueller (2011). The items for knowledge sharing behavior constructs are adapted from Lin and Lee (2004) and Hsu et al (2007). The respondents indicated the degree of their opinion by rating it on a five-point Likert scale where SD ="strongly disagreed", $\mathrm{D}=$ disagreed", $\mathrm{N}=$ "somewhat agree", $\mathrm{A}=$ "agree", $\mathrm{SA}=$ "strongly agree".

\section{Results and Findings}

The findings of the descriptive statistics indicate that $59.4 \%$ of the respondents were male and the remaining $40.6 \%$ were females. Among four age groups of participants, 3\% were between 21-30 years old, 32.3\% between 31-40 years old, $37.63 \%$ between $41-50$ years old and $27.1 \%$ above 50 years old. Based on the findings, $20.3 \%$ of the participants were Professors, $29.3 \%$ were Associate Professor and 50.4\% were Lecturer. In addition, $18 \%$ of the respondents have worked between 1 to 10 years, 29.3\% between 11 to 20 years, 23.3\% between 21 to 30 years, $27.1 \%$ between 31 to 40 years and $2.3 \%$ more than 40 years. Finally, Table 1 depicts the summary of the descriptive analysis results of the respondents' demographic profile. 
Table 1: Summary of the Descriptive Analysis Result

\begin{tabular}{|c|c|c|c|}
\hline & & Frequency & Percentage \\
\hline \multirow{3}{*}{ Gender } & Male & 79 & 59.4 \\
\cline { 2 - 4 } & Female & 54 & 40.6 \\
\hline \multirow{4}{*}{ Age } & $21-30$ & 4 & 3.0 \\
\cline { 2 - 4 } & $31-40$ & 43 & 32.3 \\
\cline { 2 - 4 } & $41-50$ & 50 & 37.6 \\
\cline { 2 - 4 } & 51 above & 36 & 27.1 \\
\hline \multirow{3}{*}{ Position } & Professor & 66 & 49.6 \\
\cline { 2 - 4 } & Associate Professor & 39 & 29.3 \\
\cline { 2 - 4 } & Lecturer & 67 & 50.4 \\
\hline \multirow{3}{*}{ Work Experience } & $1--10$ & 24 & 18.0 \\
\cline { 2 - 4 } & $11--20$ & 39 & 29.3 \\
\cline { 2 - 4 } & $21-30$ & 36 & 23.3 \\
\cline { 2 - 4 } & $31-40$ & 3 & 27.1 \\
\cline { 2 - 4 } & 40 above & & 2.3 \\
\hline
\end{tabular}

Samples, $N=133$

\subsection{Results of Hypotheses Testing}

As mentioned earlier, the data gathered was empirically tested using the multiple regressions via the SPSS software version 21. The multiple regressions are usually used to predict and weigh the relationship between a group of independent variables and a single dependent variable. To examine these hypotheses, all the variables were entered in a single block to run the regression analysis using the SPSS software. It was found that the proposed model explains a significant percentage of variance to show the influence of personality trait factors on knowledge sharing. Anova was calculated to determine if the model has a good-fit for the data. The results demonstrate that the relationship between the independent variables and dependent variable is very strong and the analysis of variance is highly statistically significant $\left(p=0.000<0.05\right.$ ). The values of $R^{2}=0.495$, Adjusted $R^{2}=0.475$, Standard error of the estimate 0.43642 were recorded.

As shown in Table 2, most the independent variables have significant influences on knowledge sharing as follows: agreeableness ( $\beta=0.88$ ), openness $(\beta=0.347)$, neuroticism $(\beta=0.016)$, extraversion $(\beta=0.175)$, and conscientiousness $(\beta=0.242)$. Furthermore, the effect of openness, conscientiousness and extraversion are statistically significant $(p=$ $0.000,0.000$ and 0.005 , respectively $<0.05$ ) while, the effect of agreeableness and neuroticism are not statistically significant $(p=0.163,0.763>0.05)$. It was observed that, relative to each other, openness exerted the utmost effect on knowledge sharing, whereas neuroticism' have a minor influence on it. Further explanations and detailed discussion on the findings will be presented in discussion section. In sum, knowledge sharing can be predicted through following equation:

Knowledge sharing $=0.592+0.88$ Agreeableness +0.347 Openness +0.016 Neuroticism +0.175 Extraversion + 0.242 Conscientiousness

Table 2: Coefficients Results

\begin{tabular}{|l|c|c|c|c|c|}
\hline \multirow{2}{*}{ Model } & \multicolumn{2}{|c|}{ Unstandardized Coefficients } & Standardized Coefficients & \multirow{2}{*}{$\mathrm{t}$} & Sig. \\
\cline { 2 - 5 } & $\mathrm{B}$ & Std. Error & Beta & & \\
\hline (Constant) & .592 & .314 & & 1.884 & .062 \\
Agreeableness & .088 & .063 & .099 & 1.402 & .163 \\
Openness & .347 & .079 & .349 & 4.410 & .000 \\
1 Neuroticism & .016 & .053 & .023 & .302 & .763 \\
Extraversion & .175 & .061 & .214 & 2.848 & .005 \\
Conscientiousness & .242 & .065 & .281 & 3.745 & .000 \\
\hline
\end{tabular}

a. Dependent Variable: Knowledge Sharing, $N=133, p<0.05$

b. $R=0.703^{a}, R$ Square $=0.495$, Adjusted R Square $=0.475$, Standard error of the estimate 0.43642 


\section{Discussion}

The results of this study denote that out of five hypotheses, four hypotheses $(\mathrm{H} 2, \mathrm{H} 3, \mathrm{H} 4$ and $\mathrm{H} 5)$ are supported. Table 3 shows the summary of the hypotheses test results. The findings of this study show that although agreeableness among academic staff $(\beta=0.088, p>.05)$ has an influence on their knowledge sharing behaviour yet it was statistically insignificant. Previous studies had found that people with high agreeableness never feel hesitate to share their information, experience and best practices. Although the findings of this study are similar to the findings of Matzler et al. (2008), which revealed that agreeableness has impact on knowledge sharing yet the findings of this current study showed that agreeableness is not statistically significant. A possible explanation to this finding therefore implies that though individuals with high level of agreeableness are said to be helpful, cheerful, cooperative and supportive at work yet these characteristics may not lead them to higher sharing of knowledge in competitive environment where research output and publications is used to judge staff key performance indicators. Therefore, hypothesis one is not supported.

The findings of this study revealed that openness to experience $(\beta=0.347, p<05)$ significantly influenced the level of knowledge sharing behavior of the academic staff. It also revealed that openness to experience is the most influencing predictor of their knowledge sharing behaviour. These results are in accordance with prior research carried out by (Hsu et al., 2007; Matzler et al., 2008; Wang and Yang; 2007), which revealed that openness to experience is directly associated with individuals' willingness to share knowledge. This finding is further supported by Cabrera et al. (2006) study which also established that openness to experience is a strong indicator of knowledge sharing. The individuals high on openness to experience exhibits active imagination, flexibility of thoughts, curiosity and receptivity of new ideas. Thus, the findings imply that academic staff with high openness to experience tends to share more knowledge. Therefore, hypothesis two is supported.

The findings of this study show that neuroticism in academic staff $(\beta=0.016, p>.05)$ has an influence on their knowledge sharing but there is not statistically significant. This implies that individuals with high neuroticism would probably be less involved in knowledge sharing as suggested to Gupta (2008). The finding of this study is in agreement with the previous study conducted by Wang and Yang (2007) which showed that neuroticism had no significant relationship with individuals' knowledge sharing intention. Individuals who have high neuroticism are characterized as insured, moody and self-conscious. They possess the common inclination to express undesirable attributes such as embarrassment, fear, sadness, anger, and guiltiness. Previous studies (Wang and Yang, 2007; Gupta 2008 and so on) had suggested that the reason why knowledge sharing activities would be interfered by neuroticism is due to the negative attributes associated with it. In addition, previous study by Costa and McCrae (1992) expressed that individuals with high neurotic tendencies are more liable to possess unreasonable ideas, less inability to manage their urges, and less likely cope effectively others. Therefore, hypothesis three is supported.

The findings of this study report that extroversion $(\beta=0.175, p<05)$ has a significant impact on level of knowledge sharing among the academic staff. The findings is consistent with the finding of previous study carried out by De Vries et al., (2006) which found extraversion to positively influence knowledge sharing. This implies that individuals with high extroversion tendencies would possibly be more involved in knowledge sharing as suggested to Gupta (2008). Previous studies (De Vries et al., 2006; Gupta, 2008) had suggested that individuals high on extroversion are more sociable, selfconfident, vigorous, bold, energetic, adventurous, and communicative. Arguably, it could be suggested that the academic staff are extraverts who have the social skills due to their level of education and exposure making them to have desire to work with others and be involved in knowledge sharing activities. According to Costa and McCrae, (1992), extraversion is a reflection of individuals' self-confidence and assertiveness. Therefore, the nature of the lecturing job which requires academic staff to be self-confident and assertiveness is probably the reason why extroversion would influence knowledge sharing. Therefore, hypothesis four is supported.

The result of this study reports that conscientiousness $(\beta=0.242, p<.05)$ has a positive statistically significant influence on the knowledge sharing. This result is similar with the finding of existing research by Matzler et al., (2008) as well as Wang and Yang, (2007), concluded that conscientiousness has a significant relationship to knowledge sharing. One possible explanation to support this study's findings is that conscientiousness reveals individuals' dispositions such as been reliable, dutiful, dependable, responsible, industrious, hardworking, organized and goal oriented. The nature of the academic job makes the respondents to possess characteristics that make them to be dutiful, responsible, industriousness, organized, hardworking and achievement oriented which could arguably be the reason why they participate in knowledge sharing activities. Therefore, hypothesis five is supported. Figure 2 depicts the final model of this study. Neuroticism though hypothetically supported yet it was removed from the final model because it exhibited a negative influence on knowledge sharing as stated in hypothesis three. Therefore, only personality traits dimension which has positive influence on knowledge sharing are incorporated into the final research model. 
Table 3: Summary of the Hypotheses Testing Results

\begin{tabular}{|l|l|l|}
\hline Hypothesis 1: & Agreeableness has a positive significant influence on knowledge sharing & Not Supported \\
\hline Hypothesis 2: & Openness to experience has a positive significant influence on knowledge sharing & Supported \\
\hline Hypothesis 3: & Neuroticism has a negative significant influence on knowledge sharing & Supported \\
\hline Hypothesis 4: & Extraversion would have a positive influence on knowledge sharing & Supported \\
\hline Hypothesis 5: & Conscientiousness would have positive influence on knowledge sharing & Supported \\
\hline Hypothesis 6 $^{\circ}$ & One of these predictors is the most dominant factor of knowledge sharing & $\begin{array}{l}\text { Openness to experience is the } \\
\text { dominant predictor }\end{array}$ \\
\hline
\end{tabular}

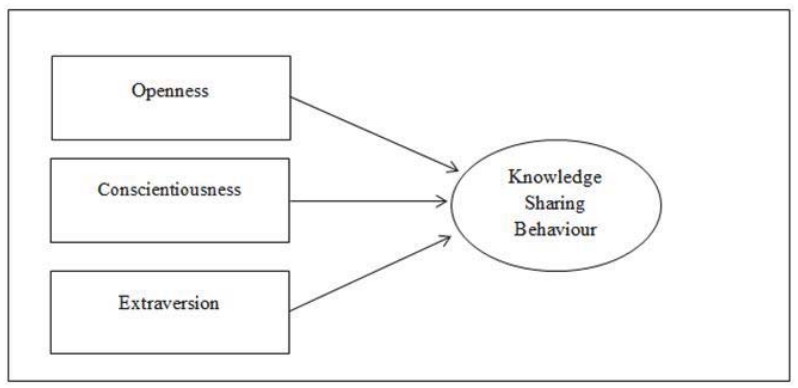

Figure 2: Final Research Model

\section{Conclusion and Recommendation}

This study has examined the influence of personality trait dimension on knowledge sharing among academics working in a research intensive university using the big five theory as the theoretical underpinning. The findings of the study indicate that personality traits dimensions are important individual characteristics that influence individual's knowledge sharing behavior. Based on the findings, we proposed a model that could be utilized as a significant framework for fostering ways in which individual factors (especially personality traits) could enhance knowledge sharing in the higher education institution. Taking these considerations into account, these factors will ensure the success of knowledge management initiatives in any institution. In sum, this study provides important insights into the role of three important dimensions of big- five personality factors (openness, extroversion, and conscientiousness) in fostering knowledge sharing behavior in the context of academic staff, and the results of this study contributes empirically to the existing literature on the factors that influence knowledge sharing.

We recommend that institutions or organizations which seek to improve knowledge sharing, should consider improving the level of agreeableness of their employees or staff. In this regard, the human capital development division could embark on interventions such as training that could help individuals' in the course of carrying out their job functions. As indicated, this study was conducted among academic staff in only one public university. Conducting the research in only one organization provides a limited room for the results to be generalized. Therefore, we recommend that future research could widen the scope to cover many universities for a more generalizability the findings.

In addition, since this study only considered the influence of personality trait dimensions and knowledge sharing using the big five theory, we recommend that future studies could extend the study by adding other individual factors from other existing theories such as the social exchange theory, social capital theory etcetera. Moderating factors such as trust, self-efficacy could be add and investigated. Finally, this study employed the quantitative methodology which arguably may not probe the personality theory in-depth. Future research could opt for the qualitative methodology to carry out a similar study or combine the quantitative and qualitative methodology in order to provide a holistic in-depth investigation.

\section{References}

Alvesson, M., \& Kärreman, D. (2001). Odd couple: making sense of the curious concept of knowledge management. Journal of management studies, 38(7), 995-1018.

Awad, E. M., \& Ghaziri, H. M. Knowledge Management, 2004: Prentice-Hall, Upper Saddle River, New Jersey. 
Barrick, M. R., \& Mount, M. K. (1991). The big five personality dimensions and job performance: a meta-analysis. Personnel psychology, 44(1), 1-26.

Barrick, M. R., Stewart, G. L., \& Piotrowski, M. (2002). Personality and job performance: test of the mediating effects of motivation among sales representatives. Journal of Applied Psychology, 87(1), 43.

Barrick, M. R., Parks, L., \& Mount, M. K. (2005). Self-Monitoring as A Moderator Of The Relationships Between Personality Traits And Performance. Personnel psychology, 58(3), 745-767.

Becerra-Fernandez, I., Gonzalez, A., \& Sabherwal, R. (2004). Knowledge Management: Challenges. Solutions and Technologies. Pearson/Prentice Hall.

Bellinger, G., Castro, D., \& Mills, A. (2004). Data, information, knowledge, and wisdom. URL: http://www.systems-thinking.org/dikw/ dikw.htm, 47.

Bennet, A., \& Bennet, D. (2000). Characterizing the next generation knowledge organization. Knowledge and Innovation: Journal of the $\mathrm{KMCl}, 1(1), 8-42$.

Benet-Martinez, V., \& John, O. P. (1998). Los Cinco Grandes across cultures and ethnic groups: Multitrait-multimethod analyses of the Big Five in Spanish and English. Journal of personality and social psychology, 75(3), 729.

Bollinger, A. S., \& Smith, R. D. (2001). Managing organizational knowledge as a strategic asset. Journal of knowledge management, 5(1), 8-18.

Cabrera, A., Collins, W. C., \& Salgado, J. F. (2006). Determinants of individual engagement in knowledge sharing. The International Journal of Human Resource Management, 17(2), 245-264.

Calantone, R. J., Cavusgil, S. T., \& Zhao, Y. (2002). Learning orientation, firm innovation capability, and firm performance. Industrial marketing management, 31(6), 515-524.

Cattell, R. B., \& Kline, P. E. (1977). The scientific analysis of personality and motivation. Academic Press.

Constant, D., Sproull, L., \& Kiesler, S. (1996). The kindness of strangers: The usefulness of electronic weak ties for technical advice. Organization science,7(2), 119-135.

Costa Jr, P. T., \& McCrae, R. R. (1992). Four ways five factors are basic. Personality and Individual Differences, 13(6), 653-665.

Davenport, T. H., \& Prusak, L. (1998). Working knowledge: How organizations manage what they know: Harvard Business Press.

De Vries, R. E., Van den Hooff, B., \& de Ridder, J. A. (2006). Explaining knowledge sharing the role of team communication styles, job satisfaction, and performance beliefs. Communication Research, 33(2), 115-135.

Eysenck, H. J., \& Eysenck, M. W. (1987). Personality and individual differences: A natural science approach, New York: Plenum.

Fullwood, R., Rowley, J., \& Delbridge, R. (2013). Knowledge sharing amongst academics in UK universities. Journal of knowledge management, 17(1), 123-136.

Grant, R. M. (1996). Toward a Knowledge-Based Theory of the firm. Strategic management journal, 17(S2), 109-122.

Gupta, A. K., \& Govindarajan, V. (2000). Knowledge flows within multinational corporations. Strategic management journal, 21(4), 473496.

Gupta, A. K., \& Govindarajan, V. (2006). Knowledge management's social dimension: lessons from Nucor Steel.

Gupta, B. (2008). Role of personality in knowledge sharing and knowledge acquisition behavior. Journal of the Indian Academy of Applied Psychology, 34(1), 143-149.

Halder, S., Roy, A., \& Chakraborty, P. (1970). The influence of personality traits on information seeking behaviour of students. Malaysian Journal of Library \& Information Science, 15(1).

Hendriks, P. (1999). Why share knowledge? The influence of ICT on the motivation for knowledge sharing. Knowledge and process management, 6(2), 91-100

Hsu, M.-H., Ju, T. L., Yen, C.-H., \& Chang, C.-M. (2007). Knowledge sharing behavior in virtual communities: The relationship between trust, self-efficacy, and outcome expectations. International Journal of Human-Computer Studies, 65(2), 153-169.

Hsieh, H.-L., Hsieh, J.-R., \& Wang, I.-L. (2011). Linking personality and innovation: The role of knowledge management. World Transactions on Engineering and Technology Education, 9(1).

Hsu, M.-H., Ju, T. L., Yen, C.-H., \& Chang, C.-M. (2007). Knowledge sharing behavior in virtual communities: The relationship between trust, self-efficacy, and outcome expectations. International Journal of Human-Computer Studies, 65(2), 153-169.

Jarvenpaa, S. L., \& Staples, D. S. (2001). Exploring perceptions of organizational ownership of information and expertise. Journal of Management Information Systems, 18(1), 151-184.

LePine, J. A., \& Van Dyne, L. (2001). Voice and cooperative behavior as contrasting forms of contextual performance: evidence of differential relationships with big five personality characteristics and cognitive ability. Journal of Applied Psychology, 86(2), 326.

Lin, H.-F. (2007). Knowledge sharing and firm innovation capability: an empirical study. International Journal of Manpower, 28(3/4), 315332.

Lin, H.-H., \& Wang, Y.-S. (2012a). Investigating the Effect of University Students' Personality Traits on Knowledge Withholding Intention: A Multi-theory Perspective. International Journal of Information and Education Technology, 2, 354-357.

Matzler, K., Renzl, B., Müller, J., Herting, S., \& Mooradian, T. A. (2008). Personality traits and knowledge sharing. Journal of Economic Psychology, 29(3), 301-313.

Matzler, K., \& Mueller, J. (2011). Antecedents of knowledge sharing-Examining the influence of learning and performance orientation. Journal of Economic Psychology, 32(3), 317-329.

McDougall, W. (1932). Of the words character and personality, Journal of Personality, 1(1), 3-16.

Mitchell, R., Nicholas, S., \& Boyle, B. (2009). The role of openness to cognitive diversity and group processes in knowledge creation. 
Small Group Research.

Moon, Y. J., Kim, W. G., \& Armstrong, D. J. (2014). Exploring neuroticism and extraversion in flow and user generated content consumption. Information \& Management, 51(3), 347-358.

Nonaka, I., \& Takeuchi, H. (1995). The knowledge-creating company: How Japanese companies create the dynamics of innovation: Oxford university press.

Rivera-Vazquez, J. C., Ortiz-Fournier, L. V., \& Flores, F. R. (2009). Overcoming cultural barriers for innovation and knowledge sharing. Journal of knowledge management, 13(5), 257-270.

Ryckman, R. (2004). Theories of personality. Thomson/Wadsworth, Belmont, CA.

Scarbrough, H. (2003). Knowledge management, HRM and the innovation process. International Journal of Manpower, 24(5), 501-516.

Soto, C. J., \& John, O. P. (2009). Ten facet scales for the Big Five Inventory: Convergence with NEO PI-R facets, self-peer agreement, and discriminant validity. Journal of Research in Personality, 43(1), 84-90.

Teh, P.-L., Yong, C.-C., Chong, C.-W., \& Yew, S.-Y. (2011). Do the Big Five Personality Factors affect knowledge sharing behaviour? A study of Malaysian universities. Malaysian Journal of Library \& Information Science, 16(1).

Tiwana, A. (2000). The knowledge management toolkit: practical techniques for building a knowledge management system: Prentice Hall PTR.

Verburg, R. M., \& Andriessen, E. J. (2011). A typology of knowledge sharing networks in practice. Knowledge and process management, 18(1), 34-44.

Van den Hooff, B., Elving, W., Meeuwsen, J. M., \& Dumoulin, C. (2003). Knowledge sharing in knowledge communities. Paper presented at the Communities and technologies.

Wasko, M. M., \& Faraj, S. (2005). Why should I share? Examining social capital and knowledge contribution in electronic networks of practice. MIS quarterly, 35-57.

Wang, S., \& Noe, R. A. (2010). Knowledge sharing: A review and directions for future research. Human Resource Management Review, 20(2), 115-131.

Wang, C.-C., \& Yang, Y.-J. (2007). Personality and intention to share knowledge: An empirical study of scientists in an R\&D laboratory. Social Behavior and Personality: an international journal, 35(10), 1427-1436.

Wang, S., Noe, R. A., \& Wang, Z.-M. (2014). Motivating Knowledge Sharing in Knowledge Management Systems A Quasi-Field Experiment. Journal of Management, 40(4), 978-1009.

Yusof, Z. M., \& Ismail, M. B. (2010). The impact of awareness, trust and personality on knowledge sharing practice. Paper presented at the Information Retrieval \& Knowledge Management,(CAMP), 2010 International Conference on Information Retrieval \& Knowledge Management.

Zack, M. H. (1999). Developing a Knowledge Strategy. California management review, 41(3), 125-145. 